\title{
Ligand Rearrangement Leads to Tetrahydrothiophene-Functionalized N,S-Heterocyclic Carbene Palladium(II) Complexes
}

\author{
Andrew M. Romine†, Matthew J. Demer†, Milan Gembickył, Arnold L. Rheingold ${ }^{\ddagger}$, and Keary M. \\ Engle*,†
}

tDepartment of Chemistry, The Scripps Research Institute, 10550 North Torrey Pines Road, La Jolla, California 92037, United States

* Department of Chemistry and Biochemistry, University of California, San Diego, 9500 Gilman Drive, Mail Code 0358, La Jolla, California 92093, United States

\begin{abstract}
Tetrahydrothiophene-functionalized $N, S$-heterocyclic carbene palladium(II) complexes are synthesized through an unexpected rearrangement that proceeds with palladium(II) trifluoroacetate and not with palladium(II) acetate, palladium(II) bromide, or palladium(II) chloride. A series of these complexes were isolated and characterized by X-ray crystallography. The mechanism of formation of these [3.2.1]-palladabicycles was explored, and the catalytic capabilities of these complexes were demonstrated in representative $\mathrm{C}-\mathrm{C}$ coupling reactions.
\end{abstract}

\section{INTRODUCTION}

The past few decades have witnessed a surge of interest in carbenes as spectator ligands in transition metal catalysis. ${ }^{1}$ An increasingly vast collection of ligands, including $N$-heterocylic carbenes (NHCs), ${ }^{2}$ cyclic (alkyl)- and (aryl)-(amino)carbenes (CAACs), ${ }^{3}$ and abnormal NHCs ( $\left.a \mathrm{NHCs}\right)^{4}$ have been developed, which collectively grant access to diverse steric and electronic properties useful in catalyst development (Scheme 1a). While much of the research on NHC-metal complexes has focused on those in which the metal is coordinated to the $\mathrm{C}$ atom between

\section{Scheme 1. Examples of Relevant Carbenes ${ }^{a}$}

A. General Structures of Selected Metal-Carbenes Classes<smiles>[M]C1C([M])N([R])CCN1[R]</smiles>

$\mathrm{N}$-Heterocyclic Carbenes (NHCs)<smiles>[R]C1C2C([M])N([R])C([R])(C1[R])C2[R]</smiles>

Cyclic Alkyl Amino Carbenes (CAACs)

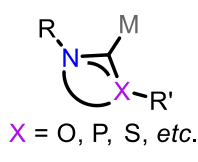

$N, X$-Heterocyclic Carbenes (NXHCs)
B. Representative N,S-Heterocyclic Carbenes (NSHCs)<smiles>[M]C1=[SH]c2ccccc2N1C</smiles>

[Caló, 2000]<smiles>[M]c1c(C=CC)n(CC)c2ccccc12</smiles>

[Hahn, 2006]<smiles>[M]c1ncc[nH]1</smiles>

[Ruiz, 2009]
C. Representative NHCs with Pendant Thioethers<smiles>CCS1=[M]C2N(C)c3ccccc3N2CC1</smiles>

[Braunstein, 2010]<smiles></smiles>

[Huynh, 2010]

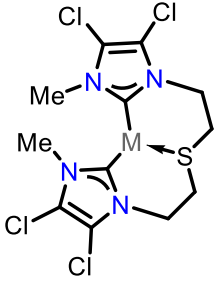

[Huynh, 2011] two nitrogen atoms in an imidazole-based framework, $1 \mathrm{~d}, 2 \mathrm{i}$ interest in similar carbenes, ${ }^{5}$ such as those where one $\mathrm{N}$ atom is replaced with an $\mathrm{O}$ (oxazole), $\mathrm{P}$ (phosphazole), or $\mathrm{S}$ (thiazole) has led to the naming system $N, X$-heterocyclic carbenes $(\mathrm{X}=0$, $\mathrm{P}, \mathrm{S}$, etc.) or NXHC (Scheme 1b). ${ }^{6}$ NXHC-metal complexes have been extensively explored, ${ }^{7}$ with a number of studies focused specifically on NSHC-metal complexes. ${ }^{6}$

Polydentate ligands containing either multiple tethered NHCs or an NHC and an additional pendant functional group, such as an aminophosphine ${ }^{8}$, an ester ${ }^{9}$, or others ${ }^{10}$ have also been synthetically explored. Notably, a number of palladium complexes bearing sulfur-containing NHCs have been characterized (Scheme 1c) ${ }^{11}$ and shown to catalyze various reactions, such as Suzuki couplings, ${ }^{12}$ Mizoroki-Heck reactions, ${ }^{13}$ asymmetric allylic alkylations, ${ }^{14}$ hydroaminations, ${ }^{15}$ direct arylations ${ }^{15 b}$, 16, Sonogashira couplings, ${ }^{17}$ and nitrile-amide interconversions. ${ }^{17}$ In catalysis,

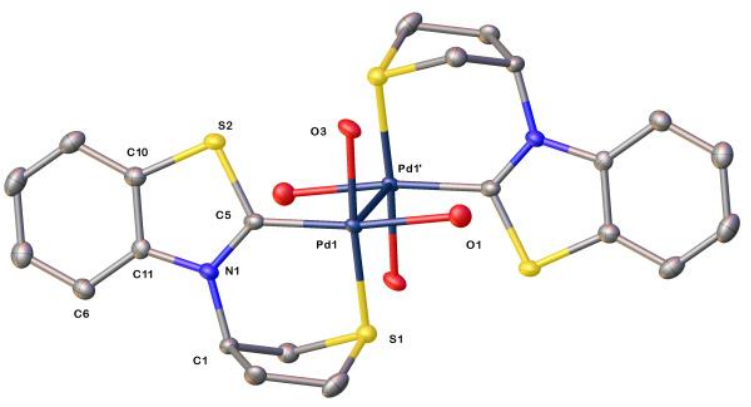

Figure 1. Molecular structure of $( \pm)$-2a showing $50 \%$ probability ellipsoids; hydrogen atoms and $(\mathrm{CO}) \mathrm{CF}_{3}$ groups from trifluoroacetate ligands are omitted for clarity. Selected bond lengths $[\AA ̊]$ and bond angles [deg]: Pd1-Pd1' 3.2086(5), Pd1-S1 2.2581(10), N1-C1 1.482(5), N1-C5 1.332(5), N1-C11 1.407(5), S2-C5 1.711(4), S2-C10 1.736(4), S1-Pd1-C5 94.21(11), C5-Pd1-03 90.14(13), 03-Pd1-01 83.25(11), 01-Pd1-S1 92.48(8), C5-Pd1-Pd1' $91.49(10)$. 
metal-bound thioethers are hemilabile ligands that, when incorporated in a polydentate ligand framework that contains one or multiple NHCs, exhibit reversible binding to the metal center; this property can be useful in ligand design, for example in stabilizing resting states while still allowing dissociation to open a coordination cite for association of reactants. ${ }^{11 \mathrm{~d}, 15 \mathrm{~b}, 18}$

\section{RESULTS AND DISCUSSION}

During the course of a previous study, ${ }^{19}$ a mixture of 2-(but3-en-1-ylthio)benzo[d]thiazole (1a) and palladium(II) trifluoroacetate $\left(\mathrm{Pd}(\mathrm{TFA})_{2}\right)$ was stirred at $45{ }^{\circ} \mathrm{C}$ in 1,2 dichloroethane (1,2-DCE) for $12 \mathrm{~h}$ in attempt to isolate a palladium species bound to both the benzothiazole directing group and pendent alkene. After filtration and vapor diffusion of diethyl ether into the filtrate, a large number of yellow crystals formed. X-ray analysis revealed these crystals to be composed of an unexpected dimeric $\mathrm{Pd}_{2}(\mathrm{NSHC})_{2}(\mathrm{TFA})_{4}$ complex containing the C,S-bidentate bridging NSHC ligand 3(tetrahydrothiophen-3-yl)benzo[d]thiazol-3-ium-2-ide

(Figure 1). This product, $( \pm)-2 a$, was isolated in $82 \%$ yield and its structure was further confirmed by ${ }^{1} \mathrm{H}-\mathrm{NMR},{ }^{13} \mathrm{C}-\mathrm{NMR}$, and high-resolution mass spectrometry (HRMS). As of yet, a palladium complex with this type of bidentate ligand based on an NSHC with pendent thioether has not been reported to the best of our knowledge. Notably, when using other palladium sources, $\mathrm{PdBr}_{2}, \mathrm{PdCl}_{2}$, and $\mathrm{Pd}(\mathrm{OAc})_{2}$, this product was not observed, suggesting that trifluoroacetate (TFA) ligands are uniquely suited for the formation of the NSHC-complex (Table 1). This may be attributed to the highly electrophilic nature of the Pd center in Pd(TFA)2, which may promote key steps in the rearrangement process (vide infra).

This complex was of interest both from a structural and mechanistic perspective. First, the formation of a bridged [3.2.1]-palladabicycle containing a five-membered tetrahydrothiophene ring is a unique structure combining both an NSHC and a pendant bridging cyclic thioether. Second, the significant rearrangement of the starting material, which involves the breaking of a $\mathrm{C}$ (benzothiazole)-S(thioether) bond and the formation of $\mathrm{C}-\mathrm{S}$ and $\mathrm{C}-\mathrm{N}$ bonds, requires an unusual mechanism. Furthermore, due to the previously demonstrated synthetic utility of this benzothiazole thioether directing group, ${ }^{19}$ greater understanding of this mechanism could lead to further applications in reaction development.

Finding this complex and its formation interesting, we sought to synthesize and characterize several similar

Table 1. Synthesis of Bidentate NSHC Pd(TFA)2 Complex $^{a}$

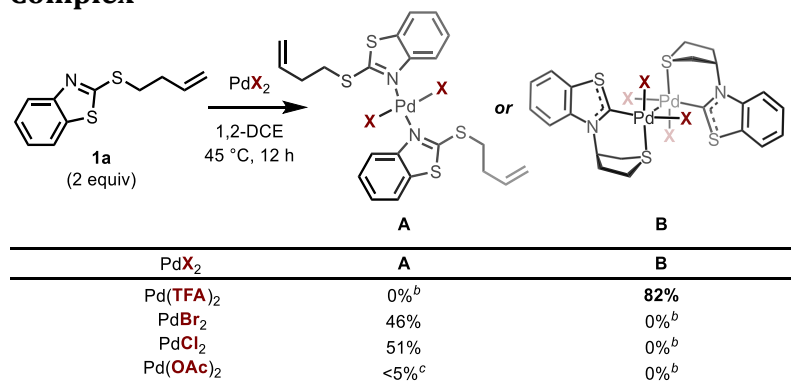

${ }^{a}$ Isolated yields calculated as percentage of total possible product. ${ }^{b}$ None isolated. ${ }^{c}$ Observed only by ${ }^{1} \mathrm{H}-\mathrm{NMR}$ as part of a complex mixture of unassignable compounds. ${ }^{d}$ None observed upon crystallization. compounds to understand the generality and limitations of this process. (S)-2-(Pent-4-en-2-ylthio)benzo[d]thiazole $((S)$-1b), which was added in 2 equiv relative to Pd(TFA) $)_{2}$, successfully provided product $\mathbf{2 b}$ ( $70 \%$ yield) (Scheme $2 \mathrm{~A}$ ), isolated as a mixture of diastereomers (d.r. $=1.4: 1$, as determined by ${ }^{1} \mathrm{H}$ NMR of the bulk solid) (Figure 2). ${ }^{1} \mathrm{H}-\mathrm{NMR}$ spectrum of this mixture shows that only two major species are present in solution, suggesting that this series of palladium complexes,

\section{Scheme 2. Scope of NSHC Products $a$}

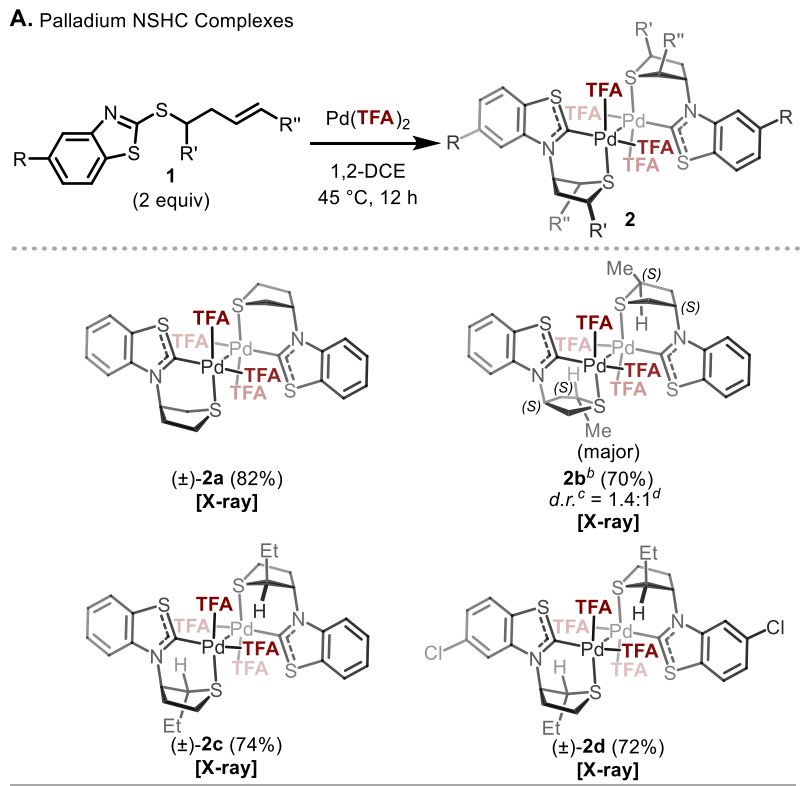

B. Unreactive Benzo[d]Thiazole-Thioethers ${ }^{e}$
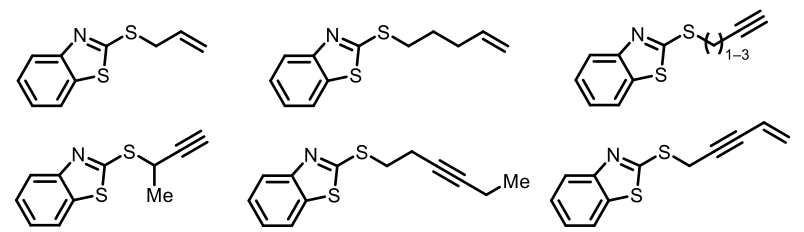

a Isolated yields calculated as percentage of total possible dimer. $b$ Product from $(S)$-2-(pent-4-en-2ylthio)benzo $[d]$ thiazole. $\quad c$ Diastereomeric ratio. ${ }^{d}$ Diastereomeric ratio of 3.3:1 was seen for racemic product due likely to solubility differences during crystallization. ${ }^{e}$ Reaction conditions: Pd(TFA) 2 ( 1 equiv), benzo[d]thiazolethioether ( 2 equiv.), 1,2 -DCE, $45^{\circ} \mathrm{C}, 12 \mathrm{~h}$, air.

\section{diastereomers from $(S)-\mathbf{1 b}$}
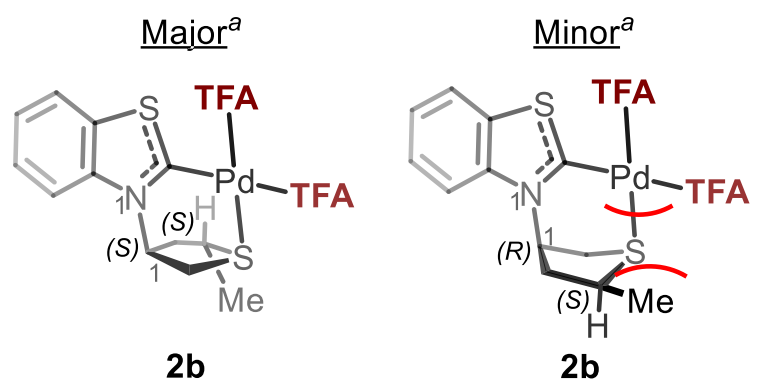

Figure 2. The two diastereomers formed in a 1.36:1 ratio, respectively, from the reaction of $(S)$-1b when analyzing the bulk solid by ${ }^{1} \mathrm{H}-\mathrm{NMR}$. ${ }^{a}$ Major and minor diastereomers observed, respectively, and identified by ${ }^{1} \mathrm{H}-\mathrm{NMR}$ and NOESY. 
while $\mathrm{Pd}-\mathrm{Pd}$ dimers in the solid state, are monomeric in solution, since three diastereomeric species would be expected in the case of dimers. Furthermore, the Pd-Pd bonds of all the dimers in crystal form are above $3.2 \AA$, suggesting semicoordination that would not persist in the presence of solvent (see Table S56 in the Supporting Information). From this sample of $\mathbf{2} \mathbf{b}$, selective crystallization of the major $(S, S ; S, S)$ diastereomer allowed for further characterization by X-ray crystallography. ${ }^{20}$ These findings suggest that the stereochemistry at the carbon-sulfur bond of the thioether in the starting material is maintained during the rearrangement, with the diastereoselectivity established in the bond-forming step between $\mathrm{C} 1$ (the carbon $\gamma$ to the sulfur of the thioether in the starting material) and $\mathrm{N} 1$ with the major diastereomer favored due to attenuated steric interactions between the methyl group and palladium.

Next, $(E)$-2-(hex-3-en-1-ylthio)benzo[d]thiazole $((E)-1 c)$, which was added in 2 equiv relative to Pd(TFA) 2 , successfully provided complex $( \pm)-2 c$ (74\% yield) (Scheme $2 \mathrm{~A}$ ). Analysis of the bulk solid by ${ }^{1} \mathrm{H}-\mathrm{NMR}$ showed that this reaction yielded a single diastereomer, and X-ray analysis of a single crystal confirmed this to be the $\mathrm{Pd}(\mathrm{TFA})_{2}$ complex with the bidentate trans-3-(2-ethyltetrahydrothiophen-3-yl)-benzo[d]thiazole-3ium-2-ide ligand. Notably, (Z)-2-(hex-3-en-1ylthio)benzo[d] thiazole $((Z)-1 c)$ does not provide any product for reasons that are not immediately obvious (Scheme 3).

Scheme 3. Thermodynamic Product from Internal E Alkene $^{a}$

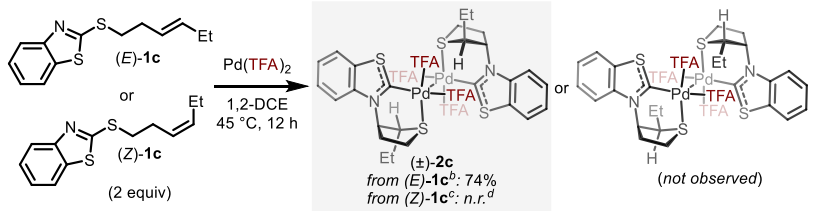

${ }^{a}$ Isolated yields calculated as percentage of total possible dimer. ${ }^{b}$ Reaction conditions: Pd(TFA) 2 (1 equiv), $(E)$-2-(hex3-en-1-ylthio)benzo[d]thiazole ( 2 equiv.), 1,2-DCE, $45^{\circ} \mathrm{C}, 12$ h, air. ${ }^{c}$ Reaction conditions: Pd(TFA) 2 (1 equiv), (Z)-2-(hex-3en-1-ylthio)benzo[d] thiazole ( 2 equiv.), 1,2-DCE, $45^{\circ} \mathrm{C}, 12 \mathrm{~h}$, air. ${ }^{d}$ No reaction.

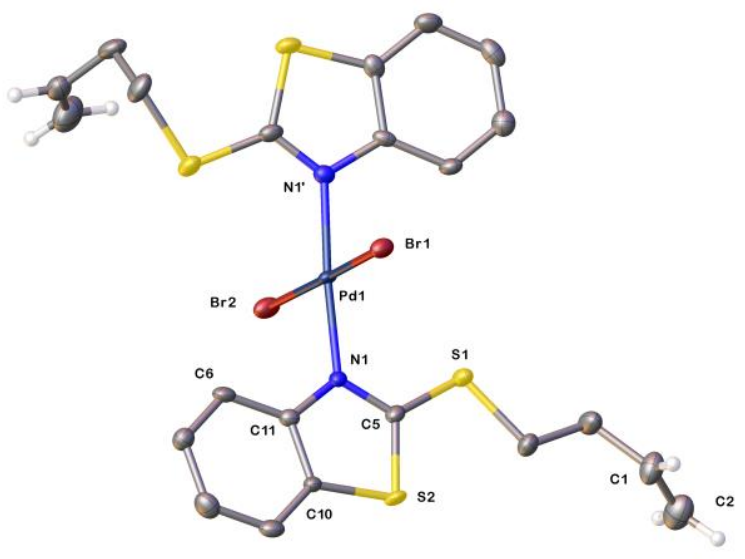

Figure 3. Molecular structure of 3a showing 50\% probability ellipsoids; hydrogen atoms not on alkene are omitted for clarity. Selected bond lengths $[\AA]$ and bond angles [deg]: Pd1-N1 2.017(4), N1-C5 1.311(7), N1-C11 1.405(7), S2-C5 1.738(6), S2-C10 1.741(6), N1-Pd1-Br1 88.81(13), N1-Pd1-Br2 90.61(13), N1'-Pd1-Br1 88.90(13), N1'-Pd1-Br2 91.86(13).
Additionally, (E)-5-chloro-2-(hex-3-en-1ylthio)benzo[d]thiazole (1d) was also subjected to the same conditions, and complex $( \pm)-2 d$ was isolated (72\% yield) (Scheme 2A). No analogous complexes were observed when attempting to use $S$-substituted benzo[d]thiazole bearing internal or terminal alkynyl, longer or shorter tethers to the alkene, or 1,1-disubstituted terminal alkenes (Scheme 2B).

In order to gain insight into the rearrangement mechanism, we revisited the results in Table 1 to more rigorously characterize the coordination mode of the substrates in nonrearranged complexes containing other counterions. Notably, complex 3a, trans- $\mathrm{PdBr}_{2}(\mathbf{1 a})_{2}$ contains two molecules of starting material coordinated through nitrogen (Figure 3). The analogous product, $\mathbf{3 b}$, was also observed with $\mathrm{PdCl}_{2}$ (see Table 1 and Figure S4 in the Supporting Information). Under the same conditions, treating $\mathrm{Pd}(\mathrm{TFA})_{2}$ with 2-((2methylbutyl)thio)benzo[d]thiazole (1e), which contains no alkene, provides the corresponding structure, 4 (Scheme 4). Of note, no evidence of palladium C5(benzothiazole)S1(thioether) insertion was observed, which suggests that C5(benzothiazole)-S1(thioether) oxidative addition occurs after cyclization onto the alkene. Next, we tested whether other transition metals can trigger this cyclization. To this end, 1a was treated with numerous commercially available salts, including those derived from nickel, copper, platinum, iron, ruthenium, and silver. From these experiments, we obtained a novel silver complex from the treatment of 2 equiv 1a with silver(I) trifluoromethanesulfonate (AgOTf), which provided complex 5 (Figure 4). In the solid-state structure, $\operatorname{Ag}(\mathrm{I})$ is simultaneously bound to the thioether, the nitrogen of the benzothiazole group in a bimetallic dimer form, and the corresponding alkene, establishing that late transition metals can indeed coordinate to the alkene moiety in the presence of a benzothiazole group. Lastly, consistent with a recent literature report, ${ }^{21}$ we found that the treatment of $\mathbf{1 a}$ with an iodine source leads the substrate to undergo iodocyclization through nitrogen to give compound 6 (Figure 4).

Based on these initial results, several possible mechanisms of formation can be envisioned. Herein we describe two plausible pathways. In both proposals, we suggest that the $\operatorname{Pd}(\mathrm{TFA})_{2}$ first coordinates to the starting material through the benzothiazole nitrogen and the alkene, as was previously

Scheme 4. Pd(TFA)2 Coordination to Benzo[d]thiazole ${ }^{a}$

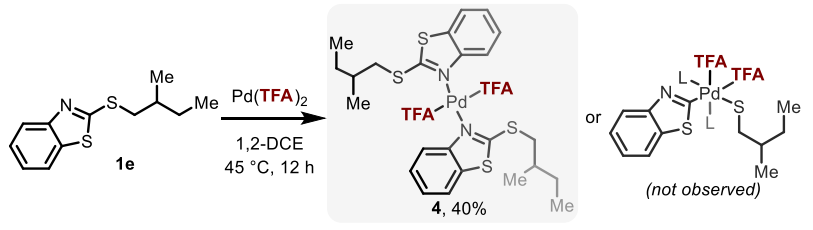

${ }^{a}$ Isolated yield.
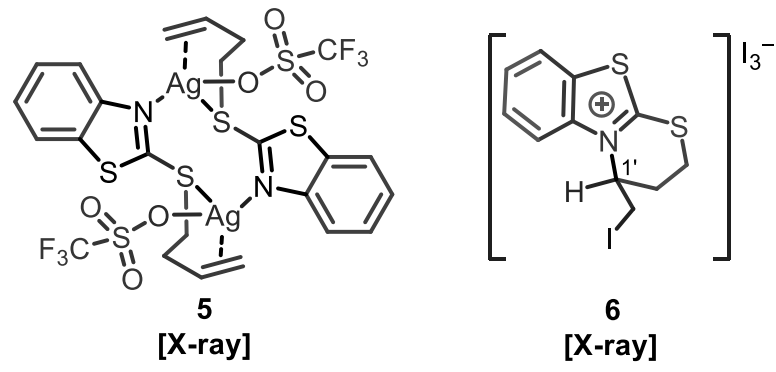

Figure 4. Isolated compounds with relevance to the proposed mechanisms. 
computationally determined for the same starting material in an oxidative-Heck reaction with $\mathrm{Pd}(\mathrm{OAc})_{2} .{ }^{19}$ While in principle this coordination could alternatively proceed through the thioether, as is seen in complex $\mathbf{5}$, or through a manner akin to complexes $\mathbf{3 a}, \mathbf{3 b}$, and $\mathbf{4}$ in which the Pd coordinates only to the benzo[d]thiazole nitrogen and not the alkene, the time course data suggests that an N1-bound-Pd(II) species coordinated to the alkene is the major species in solution (vide infra). After substrate coordination, the first mechanistic proposal involves a cyclization via anti-aminopalladation, with the benzothiazole nitrogen acting as the nucleophile, similar to the known cyclization induced by iodine. This cyclization step most likely requires a highly electrophilic Pd, which explains the unique reactivity observed with $\mathrm{Pd}(\mathrm{TFA})_{2}$ over $\mathrm{Pd}(\mathrm{OAc})_{2}$, $\mathrm{PdBr}_{2}$, and $\mathrm{PdCl}_{2}$. This could then be followed by intramolecular oxidative addition into the now weakened C5(benzothiazole)-S1(thioether) bond.22 Following this, a $\mathrm{C} 2\left(\mathrm{sp}^{3}\right)-\mathrm{S} 1 \mathrm{~S}_{\mathrm{N}} 2$-type reductive elimination would need to occur in a stereoinvertive fashion, as has been observed previously in $\mathrm{C}\left(\mathrm{sp}^{3}\right)$-heteroatom reductive elimination from

\section{Scheme 5. Plausible Mechanisms of Formation}
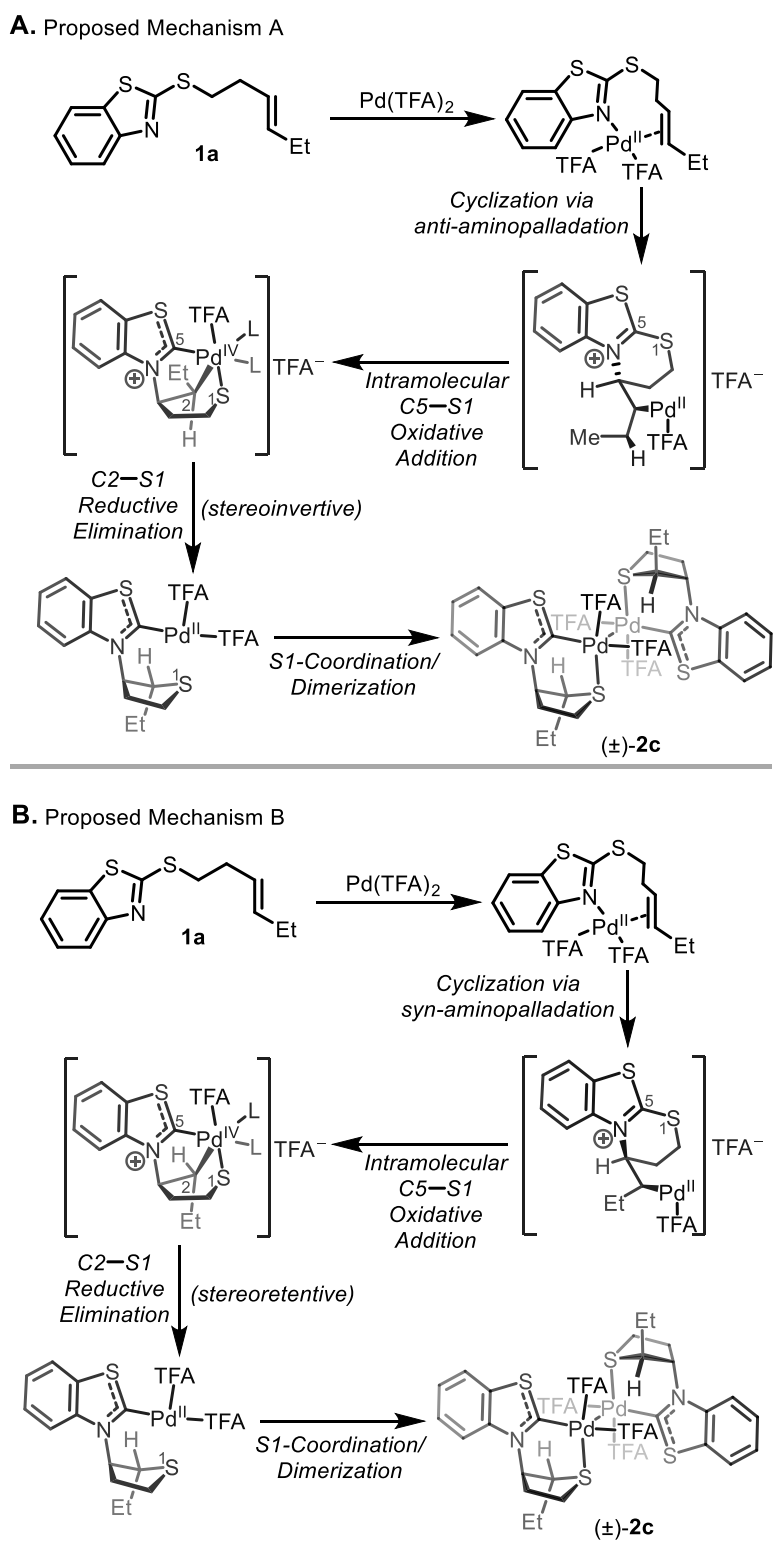

Pd(IV) centers. ${ }^{23}$ This inversion would provide the observed final product upon S1-coordination and complex dimerization (Scheme 5A). Alternatively, a cyclization could occur first through a syn-aminopalladation that, when followed by oxidative addition into the C5(benzothiazole)-S1(thioether) bond and stereoretentive $\mathrm{C} 2\left(\mathrm{sp}^{3}\right)-\mathrm{S} 1$ reductive elimination, would lead to the observed product upon thioether coordination and dimerization (Scheme 5B).

To further probe the viability of the proposed mechanisms, we monitored reaction progress over time with two model substrates, $1 \mathrm{a}$ and $1 \mathrm{c}$ at $45^{\circ} \mathrm{C}$ under air in $\mathrm{CDCl}_{3}$ by setting up a series of parallel trials and halting them at predetermined time points; we then assayed the solution $\left(\mathrm{CDCl}_{3}\right)$ and precipitate (DMSO- $\mathrm{d}_{6}$ ). In both reaction sets, a new downfield peak was observed at $9.31 \mathrm{ppm}$ in $\mathrm{CDCl}_{3}$ upon mixing of $\mathbf{1 a}$ or 1c with $\operatorname{Pd}(\mathrm{TFA}) 2$. Based on shift, integration, and data from analogous compounds $\mathbf{3 a}, \mathbf{3 b}$, and $\mathbf{4}$, this peak was assigned to the N-bound-Pd(II) species. This species was short-lived for the reaction with terminal alkene 1a (Figure 5) and persistent in the reaction with the internal alkene 1c suggesting that the initial cyclization is much faster for the terminal alkene. In the time-course experiment with $\mathbf{1 c}$, a downfield shift by $0.10 \mathrm{ppm}$

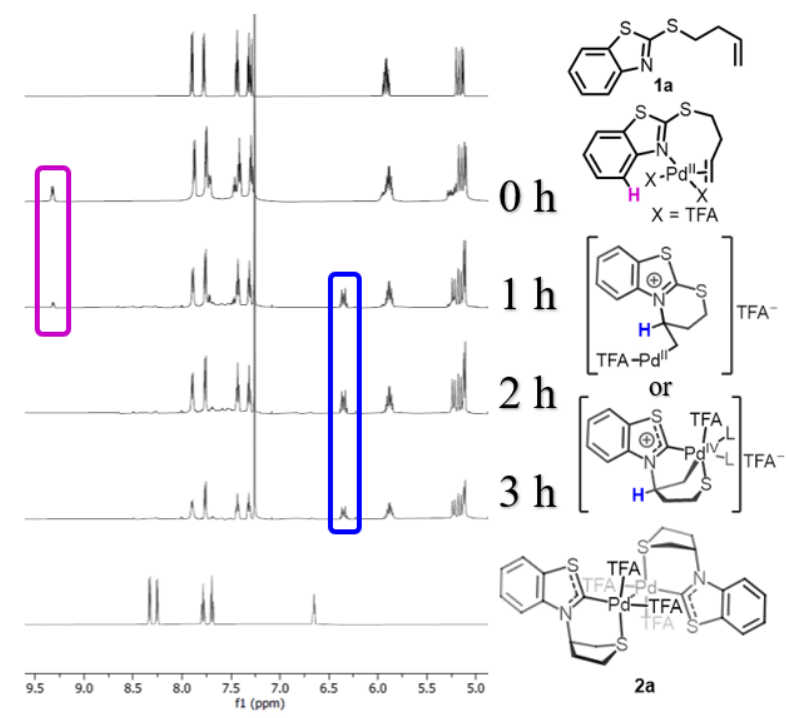

Figure 5. Time course of reaction between $\mathbf{1 a}$ and $\mathrm{Pd}(\mathrm{TFA})_{2}$ to yield $\mathbf{2 a}$, taken in $\mathrm{CDCl}_{3}$ with important new peaks highlighted. Full ${ }^{1} \mathrm{H}-\mathrm{NMRs}$, precipitate analysis (DMSO- $\mathrm{d}_{6}$ ), and the time course experiment with 1c are available in the supporting information.

\section{Scheme 6. Catalytic Reactions with Complex 1}

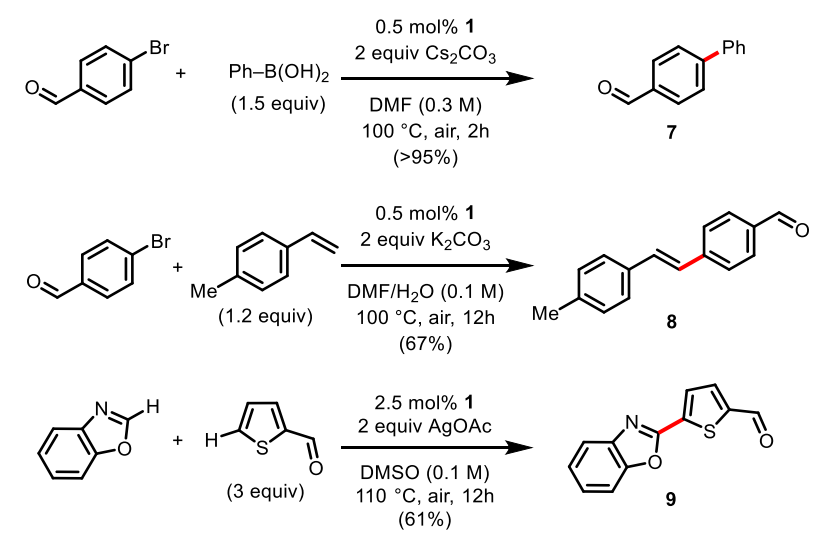


of the alkene protons is observed, and the new ${ }^{1} \mathrm{H}$ resonances integrate in a 1:1:1 ratio with the aryl proton peak at $9.31 \mathrm{ppm}$, suggesting formation of a stable intermediate with palladium coordinated to the alkene, such as is seen with silver in complex 8, and to the benzothiazole nitrogen (and not the thioether). Furthermore, at 1-3 h, novels peaks at 5.88 and $6.51 \mathrm{ppm}$ for the reaction with $\mathbf{1 a}$ in $\mathrm{CDCl}_{3}$ and DMSO-d6, respectively, are observed, consistent with the proposed cyclized intermediates. Similarly, the corresponding cyclic alkyl proton at 1' in 6 (Figure 4) is significantly downfield at 5.58-5.51 ppm in DMSO- $\mathrm{d}_{6}{ }^{21}$ Similar compounds, such as 2,3dihydro[1,3]thiazolo[2,3-b][1,3]benzothiazol-4-ium

bromide, ${ }^{24}$ also show downfield cyclic alkyl protons around 5 ppm in DMSO-d6.

Finally, several representative $\mathrm{C}-\mathrm{C}$ coupling reactions were explored using complex ( \pm )-2a as a catalyst (Scheme 6 ). In a Suzuki-Miyaura coupling, 7 was isolated in a quantitative yield when using $0.5 \mathrm{~mol} \%$ complex $( \pm)-2 \mathrm{a}$ as a catalyst. Notably, this reaction was run sealed in a vial under air demonstrating the oxidation resistance of carbene ligands compared to phosphines that typically require inert atmosphere for this transformation. Complex $( \pm)-2 \mathbf{a}$ was also a competent catalyst for the Heck reaction at $0.5 \mathrm{~mol} \%$ to provide 8 in moderate yield. A dehydrogenative cross coupling between oxazole and 2-thiophenecarboxaldehyde using $2.5 \mathrm{~mol} \%$ complex ( \pm )-2a as catalyst gave 9 in moderate yield, with much of the remaining material being homocoupling, mostly of oxazole.

\section{CONCLUSIONS}

We have herein identified a novel rearrangement leading to tetrahydrothiophene-functionalized NSHC palladium(II) complexes. Using X-ray, NMR, and HRMS data, the identity of these [3.2.1]-palladabicyclic products were confirmed. Through the synthesis of analogous complexes as well as the monitoring of reaction progress of the formation of $( \pm)-2 a$ and $( \pm)-2 c$, two plausible and closely related mechanisms can be proposed. Understanding this rearrangement process may bolster use of the benzo[d]thiazole directing group in catalytic alkene functionalization reactions. Additionally, $( \pm)-2 a$ can successfully catalyze three $\mathrm{C}-\mathrm{C}$ coupling reactions, suggesting that complexes containing bidentate NSHC ligands can be developed and explored further as a new class of catalysts.

\section{EXPERIMENTAL SECTION}

General Information. Except where otherwise stated, all materials were used as received from commercial sources without further purification. All reactants, reagents, and solvents unless otherwise mentioned were purchased from Aldrich, Alfa Aesar, Oakwood, and Combi-Blocks and used without further drying or purification. All reactions were run in an atmosphere of air. NMR spectra were recorded on an AV600 machine. Spectra were internally referenced to $\mathrm{SiMe}_{4}$, solvent signal, or internal standard. The following abbreviations (or combinations thereof) were used to explain multiplicities: $\mathrm{s}=$ singlet, $\mathrm{d}=$ doublet, $\mathrm{t}=$ triplet, $\mathrm{q}=$ quartet, $\mathrm{p}$ = pentet, $\mathrm{m}=$ multiplet. High-resolution mass spectra (HRMS) for new compounds were obtained with Waters I-Class LC with diode array and G2-XS time of flight (TOF) mass spectrometer or with an Agilent LC/MSD TOF mass spectrometer.

Synthesis of Complexes $( \pm)-2 a-4$. To a 1-dram (4 mL) vial equipped with a magnetic stir bar was added the corresponding benzo[d]thiazole-containing material $(0.2$ mmol, 2 equiv) and the palladium-containing material ( $\left.\mathrm{PdX}_{2}\right)$ $(0.1 \mathrm{mmol}, 1$ equiv). To this mixture was added $1,2-\mathrm{DCE}(1 \mathrm{~mL}$,
$0.1 \mathrm{M}$ ) and the vial was capped. The reaction was stirred at 500 rpm at $45{ }^{\circ} \mathrm{C}$ for $12 \mathrm{~h}$. Without cooling to room temperature, the crude solution was transferred into a new 1-dram (4 mL) vial. This uncapped vial with the crude mixture was placed inside a scintillation vial $(20 \mathrm{~mL})$. Diethyl ether $(2 \mathrm{~mL})$ was added to the scintillation vial without any addition into the 1dram vial containing the crude material in preparation for vapor diffusion. The scintillation vial was capped and allowed to sit undisturbed for $72 \mathrm{~h}$. The 1-dram vial was then removed from the scintillation vial and the solvent carefully removed with a pipette leaving crystals, which were washed with additional diethyl ether $(3 \times 3 \mathrm{~mL})$. The remaining diethyl ether was then removed in vacuo to provide the pure product.

Complex $( \pm)-2 a$ : The title compound was prepared with 2(but-3-en-1-ylthio)benzo[d]thiazole (1a) and Pd(TFA) 2 at $0.300 \mathrm{mmol}$ scale. Purification afforded $( \pm)-\mathbf{2 a}$ as a yellow crystal $(137 \mathrm{mg}, 41 \%) .{ }^{1} \mathrm{H}$ NMR $(600 \mathrm{MHz}$, Acetone-d 6$) \delta 8.33$ (d, $J=8.6 \mathrm{~Hz}, 1 \mathrm{H}), 8.25$ (dd, $J=8.1,1.2 \mathrm{~Hz}, 1 \mathrm{H}), 7.79$ (ddd, $J=$ $8.5,7.2,1.2 \mathrm{~Hz}, 1 \mathrm{H}), 7.72-7.67(\mathrm{~m}, 1 \mathrm{H}), 6.65(\mathrm{t}, J=5.6 \mathrm{~Hz}, 1 \mathrm{H})$, $4.14(\mathrm{tt}, J=8.4,5.0 \mathrm{~Hz}, 1 \mathrm{H}), 3.81(\mathrm{~d}, J=13.9 \mathrm{~Hz}, 1 \mathrm{H}), 3.51-3.42$ (m, 2H), 3.12-3.03 (m, 1H), 2.89-2.84 (m, 1H). ${ }^{13} \mathrm{C}$ NMR (151 $\left.\mathrm{MHz}, \mathrm{DMSO}-\mathrm{d}_{6}\right) \delta 178.37,142.99,132.90,127.91,126.74$, $123.18,115.44,66.23,45.11,41.96,38.51,34.19$. HRMS calcd. for $\mathrm{C}_{13} \mathrm{H}_{11} \mathrm{~F}_{3} \mathrm{NO}_{2}{ }^{106} \mathrm{PdS}_{2}{ }^{+} \quad[\mathrm{M} / 2-\mathrm{TFA}]^{+}$: 439.9218, Found: 439.9219. Single crystals suitable for X-ray diffraction were obtained directly from the procedure described above (CCDC 2057872).28

Complex 2b: The title compound was prepared with 2(pent-4-en-2-ylthio)benzo[d]thiazole (1b) and Pd(TFA)2. Purification afforded $\mathbf{2 b}$ as a yellow crystal ( $40 \mathrm{mg}$, 35\%) with a $d . r .=1.4: 1$ when $(S)$-2-(pent-4-en-2-ylthio)benzo[d]thiazole was used and a d.r. $=1: 3.3$ when the racemic starting material was used. ${ }^{1} \mathrm{H}$ NMR $(600 \mathrm{MHz}$, Acetone-d 6$) \delta 8.31-8.23(\mathrm{~m}, 2 \mathrm{H})$, $7.78(\mathrm{dtd}, J=8.5,7.2,1.2 \mathrm{~Hz}, 1 \mathrm{H}), 7.69$ (ddt, $J=8.2,7.2,1.9 \mathrm{~Hz}$, $1 \mathrm{H}), 6.65(\mathrm{t}, J=4.9 \mathrm{~Hz}, 0.55 \mathrm{H}), 6.57(\mathrm{t}, J=6.0 \mathrm{~Hz}, 0.42 \mathrm{H}), 4.85$ (h, $J=7.2 \mathrm{~Hz}, 0.59 \mathrm{H}), 3.93(\mathrm{dt}, J=9.2,6.8 \mathrm{~Hz}, 0.45 \mathrm{H}), 3.81$ (d, $J$ $=14.2 \mathrm{~Hz}, 1 \mathrm{H}), 3.66(\mathrm{dd}, J=14.1,4.3 \mathrm{~Hz}, 0.55 \mathrm{H}), 3.59(\mathrm{dd}, J=$ $14.0,4.8 \mathrm{~Hz}, 0.39 \mathrm{H}), 3.42-3.34(\mathrm{~m}, 0.43 \mathrm{H}), 3.13-3.06(\mathrm{~m}$, $0.44 \mathrm{H}), 2.56$ (ddd, $J=14.5,7.2,5.7 \mathrm{~Hz}, 0.50 \mathrm{H}), 2.40-2.32(\mathrm{~m}$, $0.45 \mathrm{H}), 1.97(\mathrm{~d}, J=6.8 \mathrm{~Hz}, 1.34 \mathrm{H}), 1.57$ (d, $J=7.1 \mathrm{~Hz}, 1.67 \mathrm{H})$. ${ }^{13} \mathrm{C}$ NMR (151 MHz, Acetone-d6) $\delta$ 181.37, 144.53, 144.32, $134.62,128.84,128.79,127.66,127.64,123.91,123.86$, 115.88, 115.77, 69.20, 66.93, 53.24, 53.13, 44.47, 44.18, 42.96, 40.41, 21.67, 21.27. HRMS calcd. for $\mathrm{C}_{14} \mathrm{H}_{13} \mathrm{~F}_{3} \mathrm{NO}_{2}{ }^{102} \mathrm{PdS}_{2}{ }^{+}$ [M/2-TFA $]^{+}:$449.9396, Found: 449.9388. Single crystals suitable for X-ray diffraction were obtained directly from the procedure described above (CCDC 2057870).28

Complex $( \pm)-2 c$ : The title compound was prepared with $(E)$-2-(hex-3-en-1-ylthio)benzo[d]thiazole $((E)-1 c)$ and $\mathrm{Pd}(\mathrm{TFA})_{2}$. Purification afforded $( \pm)-2 \mathrm{c}$ as an orange crystal (43 $\mathrm{mg}, 37 \%) .{ }^{1} \mathrm{H}$ NMR (600 MHz, Acetone-d 6$) \delta 8.39$ (dd, $J=8.9$, $3.3 \mathrm{~Hz}, 1 \mathrm{H}), 8.25(\mathrm{~d}, J=7.8 \mathrm{~Hz}, 1 \mathrm{H}), 7.80-7.74(\mathrm{~m}, 1 \mathrm{H}), 7.74-$ $7.67(\mathrm{~m}, 1 \mathrm{H}), 6.35(\mathrm{~d}, J=6.4 \mathrm{~Hz}, 1 \mathrm{H}), 4.18-4.06(\mathrm{~m}, 2 \mathrm{H}), 3.59$ (ddd, $J=14.3,10.6,5.1 \mathrm{~Hz}, 1 \mathrm{H}), 3.16(\mathrm{ddt}, J=16.3,11.5,5.9 \mathrm{~Hz}$, 1H), $1.91-1.80(\mathrm{~m}, 1 \mathrm{H}), 1.20(\mathrm{td}, J=7.6,2.9 \mathrm{~Hz}, 3 \mathrm{H}) .{ }^{13} \mathrm{C}$ NMR $\left(151 \mathrm{MHz}\right.$, Acetone- $\left.\mathrm{d}_{6}\right) \delta 180.18,143.14,132.90,127.40$, $126.27,122.45,116.55,114.60,114.26,70.13,60.09,43.94$, $36.08,32.22,29.24,24.09$, 11.12. HRMS calcd. for $\mathrm{C}_{15} \mathrm{H}_{15} \mathrm{~F}_{3} \mathrm{NO}_{2}{ }^{106} \mathrm{PdS}_{2}{ }^{+}$[M/2-TFA] ${ }^{+}$: 467.9531, Found: 467.9530. Single crystals suitable for X-ray diffraction were obtained directly from the procedure described above in a triclinic structure (CCDC 2057864) ${ }^{28}$ and regrown from $\mathrm{CDCl}_{3}$ in a trigonal structure (CCDC 2057865). ${ }^{28}$

Complex $( \pm)-2 d$ : The title compound was prepared with (E)-5-chloro-2-(hex-3-en-1-ylthio)benzo[d]thiazole (1d) and 
Pd(TFA) 2. Purification afforded $( \pm)-2 d$ as an orange crystal (45 $\mathrm{mg}, 36 \%) .{ }^{1} \mathrm{H}$ NMR $(600 \mathrm{MHz}$, Acetone-d 6$) \delta 8.57-8.49(\mathrm{~m}, 1 \mathrm{H})$, $8.27(\mathrm{~d}, J=8.6 \mathrm{~Hz}, 1 \mathrm{H}), 7.79-7.60(\mathrm{~m}, 1 \mathrm{H}), 6.37(\mathrm{~d}, J=6.7 \mathrm{~Hz}$, $1 \mathrm{H}), 4.22-4.06(\mathrm{~m}, 2 \mathrm{H}), 3.72-3.52(\mathrm{~m}, 1 \mathrm{H}), 3.25-3.08(\mathrm{~m}, 1 \mathrm{H})$, 2.94-2.86 (m, 1H), 2.26-2.06 (m, 1H), 1.86 (dddd, $J=17.6,15.0$, 8.4, $5.0 \mathrm{~Hz}, 2 \mathrm{H}), 1.20(\mathrm{q}, J=8.1 \mathrm{~Hz}, 3 \mathrm{H}) .{ }^{13} \mathrm{C}$ NMR $(151 \mathrm{MHz}$, Acetone-d6) $\delta$ 183.13, 144.60, 133.85, 132.15, 127.03, 124.14, $115.42,115.13,115.06,70.98,60.60,44.42,36.61,32.65$, $24.51,11.59$. HRMS calcd. for $\mathrm{C}_{15} \mathrm{H}_{14} \mathrm{ClF}_{3} \mathrm{NO}_{2}{ }^{104} \mathrm{PdS}_{2}{ }^{+}[\mathrm{M} / 2-$ $\mathrm{TFA}^{+}$: 499.9147, Found: 499.9134. Single crystals suitable for $\mathrm{X}$-ray diffraction were obtained directly from the procedure described above (CCDC 2057869). ${ }^{28}$

Complex 3a: The title compound was prepared with 2-(but3-en-1-ylthio)benzo[d]thiazole (1a) and $\mathrm{PdBr}_{2}$. Purification afforded 3a as a yellow crystal (33 mg, 46\%). ${ }^{1} \mathrm{H}$ NMR (600 $\left.\mathrm{MHz}, \mathrm{CDCl}_{3}\right) \delta 9.16(\mathrm{~d}, J=8.3 \mathrm{~Hz}, 0.75 \mathrm{H}), 9.08(\mathrm{~d}, J=8.2 \mathrm{~Hz}$, $0.25 \mathrm{H}), 7.71(\mathrm{~d}, J=7.9 \mathrm{~Hz}, 1 \mathrm{H}), 7.67(\mathrm{t}, J=8.0 \mathrm{~Hz}, 1 \mathrm{H}), 7.44(\mathrm{t}, J$ $=7.5 \mathrm{~Hz}, 1 \mathrm{H}), 5.99(\mathrm{td}, J=16.9,6.9 \mathrm{~Hz}, 1 \mathrm{H}), 5.40-5.11(\mathrm{~m}, 2 \mathrm{H})$, 3.50-3.38 (m, 2H), 2.86-2.70 (m, 2H). ${ }^{13} \mathrm{C}$ NMR (151 MHz, $\left.\mathrm{CDCl}_{3}\right) \delta 174.35,173.72,150.39,134.93,134.86,131.22$, $131.11,127.78,125.72,122.72,122.62,121.35,121.26$, $118.23,118.06,35.50,35.45,33.08,32.96,29.86$. HRMS calcd. for $\mathrm{C}_{22} \mathrm{H}_{24}{ }^{79} \mathrm{BrN}_{2}{ }^{106} \mathrm{PdS}_{4}{ }^{+} \quad[\mathrm{M}-\mathrm{Br}+2 \mathrm{H}]^{+}$: 628.9041, Found: 628.9022. Single crystals suitable for X-ray diffraction were obtained directly from the procedure described above (CCDC 2057868).28

Complex 3b: The title compound was prepared with 2(but-3-en-1-ylthio)benzo[d]thiazole (1a) and $\mathrm{PdCl}_{2}$. Crystals were regrown to X-ray quality by slow evaporation of $\mathrm{CDCl}_{3}$ in an NMR tube. Purification afforded $\mathbf{3 b}$ as a yellow crystal (32 $\mathrm{mg}, 51 \%) .{ }^{1} \mathrm{H}$ NMR $\left(600 \mathrm{MHz}, \mathrm{CDCl}_{3}\right) \delta 9.26(\mathrm{dt}, J=8.3,0.9 \mathrm{~Hz}$, $0.65 \mathrm{H}), 9.18(\mathrm{dt}, J=8.2,0.9 \mathrm{~Hz}, 0.35 \mathrm{H}), 7.76-7.71(\mathrm{~m}, 1 \mathrm{H}), 7.68$ (ddd, $J=8.4,7.3,1.2 \mathrm{~Hz}, 1 \mathrm{H}$ ), 7.45 (dddd, $J=8.2,7.2,6.1,1.1 \mathrm{~Hz}$, $1 \mathrm{H}), 6.04-5.93(\mathrm{~m}, 1 \mathrm{H}), 5.36-5.18(\mathrm{~m}, 2 \mathrm{H}), 3.48-3.42(\mathrm{~m}, 2 \mathrm{H})$, 2.82-2.71 (m, 2H). ${ }^{13} \mathrm{C}$ NMR (151 MHz, $\left.\mathrm{CDCl}_{3}\right) \delta 173.90,173.27$, $166.39,152.87,149.53,135.26,134.77,134.33,134.25$, $130.67,130.56,127.32,125.57,125.16,125.13,123.73$, $121.85,121.70,121.05,120.77,120.69,120.50,117.65$, $117.48,116.51,34.82,34.80,32.90,32.42,32.30,29.27$. HRMS calcd. for $\mathrm{C}_{22} \mathrm{H}_{22}{ }^{35} \mathrm{ClN}_{2}{ }^{106} \mathrm{PdS}_{4}{ }^{+}[\mathrm{M}-\mathrm{Cl}]+$ : 582.9386, Found: 582.9402. Single crystals suitable for X-ray diffraction were obtained directly from the procedure described above (CCDC 2051103). ${ }^{28}$

Complex 4: The title compound was prepared with 2-( (2methylbutyl)thio)benzo[d]thiazole (1e) and $\mathrm{Pd}(\mathrm{TFA})_{2}$. Purification afforded 4 as an orange crystal $(23 \mathrm{mg}, 40 \%) .{ }^{1} \mathrm{H}$ NMR $\left(600 \mathrm{MHz}, \mathrm{CDCl}_{3}\right) \delta 9.30(\mathrm{dd}, J=11.2,8.4 \mathrm{~Hz}, 1 \mathrm{H}), 7.70$ $(\mathrm{dq}, J=12.6,8.8 \mathrm{~Hz}, 2 \mathrm{H}), 7.44(\mathrm{t}, J=7.7 \mathrm{~Hz}, 1 \mathrm{H}), 3.37$ (ddd, $J=$ $13.1,7.8,5.9 \mathrm{~Hz}, 1 \mathrm{H}$ ), 3.25-3.16 (m, 1H), 2.00 (qd, $J=13.7,6.7$ $\mathrm{Hz}, 1 \mathrm{H}), 1.68(\mathrm{dtt}, J=13.0,10.1,6.3 \mathrm{~Hz}, 1 \mathrm{H}), 1.44(\mathrm{dpd}, J=14.8$, $7.4,3.0 \mathrm{~Hz}, 1 \mathrm{H}), 1.19$ (dd, $J=6.7,4.2 \mathrm{~Hz}, 3 \mathrm{H}), 1.01(\mathrm{q}, J=7.1 \mathrm{~Hz}$, $3 \mathrm{H}) .{ }^{13} \mathrm{C}$ NMR (151 MHz, $\left.\mathrm{CDCl}_{3}\right) \delta 176.59,176.41,149.81$, $149.72,130.54,130.42,128.08,127.98,125.81,125.78$, $122.02,122.00,121.18,43.14,43.04,35.07,35.01,28.98$, 28.94, 19.01, 11.37. HRMS calcd. for $\mathrm{C}_{26} \mathrm{H}_{30} \mathrm{~F}_{3} \mathrm{~N}_{2} \mathrm{O}_{2}{ }^{106} \mathrm{PdS}_{4}{ }^{+}[\mathrm{M}-$ TFA] ${ }^{+}$: 693.0177, Found: 693.0168. Single crystals suitable for $\mathrm{X}$-ray diffraction were obtained directly from the procedure described above (CCDC 2057871). ${ }^{28}$

Synthetic Procedure for Complex 5. To a 1-dram (4 mL) vial equipped with a magnetic stir bar was added 2-(but-3-en1-ylthio)benzo[d]thiazole (1a) $(0.10 \mathrm{mmol}, 2$ equiv) and the silver triflate (AgOTf) ( $0.05 \mathrm{mmol}, 1$ equiv). To this mixture was added 1,2-DCE $(0.5 \mathrm{~mL}, 0.1 \mathrm{M})$, and the vial was capped. The reaction was stirred at $500 \mathrm{rpm}$ at $45^{\circ} \mathrm{C}$ for $12 \mathrm{~h}$. Without cooling to room temperature, the crude solution was transferred into a new 1-dram (4 mL) vial. This uncapped vial with the crude mixture was placed inside a scintillation vial $(20$ $\mathrm{mL})$. Diethyl ether (2 $\mathrm{mL})$ was added to the scintillation vial without any addition into the 1-dram vial containing the crude material in preparation for vapor diffusion. The scintillation vial was capped and allowed to sit undisturbed for $72 \mathrm{~h}$. The 1 dram vial was then removed from the scintillation vial and the solvent carefully removed with a pipette leaving crystals, which were washed with additional diethyl ether $(3 \times 3 \mathrm{~mL})$. The remaining diethyl ether was then removed in vacuo to provide the pure product 5 as a grey crystal (20 mg, 42\%).

${ }^{1} \mathrm{H}$ NMR (600 MHz, Acetone- $\left.\mathrm{d}_{6}\right) \delta 8.12(\mathrm{dd}, J=15.3,8.2 \mathrm{~Hz}$, 2H), 7.59 (ddd, $J=8.3,5.0,1.3 \mathrm{~Hz}, 1 \mathrm{H}), 7.56-7.49(\mathrm{~m}, 1 \mathrm{H}), 6.24$ (ddtd, $J=13.4,8.4,6.7,1.8 \mathrm{~Hz}, 1 \mathrm{H}), 5.45-5.36(\mathrm{~m}, 2 \mathrm{H}), 3.71(\mathrm{td}$, $J=6.5,1.8 \mathrm{~Hz}, 2 \mathrm{H}), 2.75(\mathrm{q}, J=6.7 \mathrm{~Hz}, 2 \mathrm{H}) .{ }^{13} \mathrm{C}$ NMR $(151 \mathrm{MHz}$, Acetone-d6) $\delta 171.79,152.45,135.76,134.98,128.28,126.71$, 122.93, 122.63, 114.01, 36.68, 33.85. HRMS calcd. for $\mathrm{C}_{11} \mathrm{H}_{11}{ }^{107} \mathrm{AgNS}_{2}{ }^{+}$[M-OTf] $:$327.9384, Found: 327.9395. Single crystals suitable for X-ray diffraction were obtained directly from the procedure described above (CCDC 2057866). ${ }^{28}$

Synthetic Procedure for 4-(iodomethyl)-3,4-dihydro2H-benzo[4,5]thiazolo[2,3-b][1,3]thiazin-5-ium triiodide (6). To a 1-dram (4 mL) vial equipped with a magnetic stir bar was added 2-(but-3-en-1-ylthio)benzo[d]thiazole (1a) $(0.5$ mmol, 1 equiv) and the samarium(II) iodide ( $\left.\mathrm{SmI}_{2}\right)(0.5 \mathrm{mmol}$, $0.1 \mathrm{M}$ solution in THF, 1 equiv). To this mixture was added 1,2DCE ( $5 \mathrm{~mL}, 0.1 \mathrm{M})$ and the vial was capped. The reaction was stirred at $500 \mathrm{rpm}$ at $45^{\circ} \mathrm{C}$ for $12 \mathrm{~h}$. Without cooling to room temperature, the crude solution was transferred into a new 1 dram $(4 \mathrm{~mL})$ vial. This uncapped vial with the crude mixture was placed inside a scintillation vial $(20 \mathrm{~mL})$. Diethyl ether $(2$ $\mathrm{mL}$ ) was added to the scintillation vial without any addition into the 1-dram vial containing the crude material. The scintillation vial was capped and allowed to sit undisturbed for $72 \mathrm{~h}$. The 1-dram vial was then removed from the scintillation vial and the solvent carefully removed with a pipette leaving crystals, which were washed with additional diethyl ether $(3 \times$ $3 \mathrm{~mL}$ ). The remaining diethyl ether was then removed in vacuo to provide the pure product. While some X-ray quality crystals were retrievable, yield of crystals appeared low $(<10 \%)$. Reaction was rerun following a literature procedure. ${ }^{21}$

${ }^{1} \mathrm{H}$ NMR $(600 \mathrm{MHz}$, DMSO-d 6$) \delta 8.32(\mathrm{dt}, J=8.3,2.0 \mathrm{~Hz}, 1 \mathrm{H})$, 8.11 (dd, $J=8.6,3.0 \mathrm{~Hz}, 1 \mathrm{H}), 7.86-7.78(\mathrm{~m}, 1 \mathrm{H}), 7.71(\mathrm{td}, J=7.7$, $3.0 \mathrm{~Hz}, 1 \mathrm{H}), 5.54(\mathrm{dh}, J=9.6,3.1 \mathrm{~Hz}, 1 \mathrm{H}), 3.74-3.66(\mathrm{~m}, 2 \mathrm{H})$, $3.67-3.54(\mathrm{~m}, 2 \mathrm{H}), 3.01$ (dq, $J=15.1,3.3 \mathrm{~Hz}, 1 \mathrm{H}), 2.46$ (ddd, $J=$ 15.5, 10.0, $4.3 \mathrm{~Hz}, 1 \mathrm{H}) .{ }^{13} \mathrm{C}$ NMR (151 MHz, DMSO) $\delta 175.83$, $140.77,128.69,127.66,127.09,123.98,114.96,55.10,23.25$, $23.16,2.10$. Single crystals suitable for X-ray diffraction were obtained directly from the procedure described above (CCDC 2057863).28

Synthetic Procedure for [1,1'-biphenyl]-4carbaldehyde (7):25 To a 1-dram (4 mL) vial equipped with a magnetic stir bar was added 4-bromobenzaldehyde $(0.3 \mathrm{mmol}$, 1 equiv), phenylboronic acid ( $0.36 \mathrm{mmol}, 1.2$ equiv), potassium carbonate $\left(\mathrm{K}_{2} \mathrm{CO}_{3}\right)$ (1.0 mmol, 2 equiv), and $( \pm)-\mathbf{2 a}(0.0015$ mmol, $0.5 \mathrm{~mol} \%$ ). To this mixture was added a 1:1 mixture of $\mathrm{H}_{2} \mathrm{O}$ :DMF (3 mL, $0.1 \mathrm{M}$ ). The vial was capped and placed on a preheated hotplate at $100{ }^{\circ} \mathrm{C}$ and stirred at $500 \mathrm{rpm}$ for $12 \mathrm{~h}$. The reaction was removed from the stir plate and allowed to cool. The contents of the vial were transferred to a separation vial with subsequent washing of $\mathrm{H}_{2} \mathrm{O}$ and EtOAc. Additional $\mathrm{H}_{2} \mathrm{O}(50 \mathrm{~mL})$ was added to the separation vial, and the desired material was extraction with EtOAc $(3 \times 50 \mathrm{~mL})$ and dried with $\mathrm{Na}_{2} \mathrm{SO}_{4}$. After the solvent was removed in vacuo, the crude residue was purified by $\mathrm{SiO}_{2}$ gel column chromatography $(5 \%$ 
EtOAc/hexanes). Purification afforded 7 as a white solid (90 $\mathrm{mg},>95 \%)$.

${ }^{1} \mathrm{H}$ NMR (600 MHz, $\left.\mathrm{CDCl}_{3}\right) \delta 10.06(\mathrm{~s}, 1 \mathrm{H}), 7.95(\mathrm{~d}, J=8.2$ $\mathrm{Hz}, 2 \mathrm{H}), 7.75(\mathrm{~d}, J=8.2 \mathrm{~Hz}, 2 \mathrm{H}), 7.64(\mathrm{~d}, J=8.1 \mathrm{~Hz}, 2 \mathrm{H}), 7.49$ (t, $J=7.8 \mathrm{~Hz}, 2 \mathrm{H}), 7.42(\mathrm{t}, J=7.5 \mathrm{~Hz}, 1 \mathrm{H}) \cdot{ }^{13} \mathrm{C} \mathrm{NMR}(151 \mathrm{MHz}$, $\left.\mathrm{CDCl}_{3}\right) \delta 192.00,147.24,139.76,135.27,130.35,129.10$, $128.56,127.75,127.44$.

Synthetic Procedure for (E)-4-(4methylstyryl)benzaldehyde $(8): 26$ To a 1 -dram $(4 \mathrm{~mL})$ vial equipped with a magnetic stir bar was added the corresponding 4-bromobenzaldehyde ( $0.3 \mathrm{mmol}, 1$ equiv), 1 methyl-4-vinylbenzene $(0.36 \mathrm{mmol}, 1.2$ equiv $)$, potassium carbonate $\left(\mathrm{K}_{2} \mathrm{CO}_{3}\right)$ (1.0 mmol, 2 equiv), and $( \pm)-2 \mathrm{a}(0.0015$ mmol, $0.5 \mathrm{~mol} \%)$. To this mixture was added a 1:1 mixture of $\mathrm{H}_{2} \mathrm{O}$ :DMF ( $3 \mathrm{~mL}, 0.1 \mathrm{M}$ ). The vial was capped and placed on a preheated hotplate at $100{ }^{\circ} \mathrm{C}$ and stirred at $500 \mathrm{rpm}$ for $12 \mathrm{~h}$. The reaction was removed from the stir plate and allowed to cool. The contents of the vial were transferred to a separation vial with subsequent washing of $\mathrm{H}_{2} \mathrm{O}$ and EtOAc. Additional $\mathrm{H}_{2} \mathrm{O}(50 \mathrm{~mL})$ was added to the separation vial, and the desired material was extraction with EtOAc $(3 \times 50 \mathrm{~mL})$ and dried with $\mathrm{Na}_{2} \mathrm{SO}_{4}$. After the solvent was removed in vacuo, the crude residue was purified by $\mathrm{SiO}_{2}$ gel column chromatography (5\% EtOAc/hexanes). Purification afforded 8 as a yellow solid (45 mg, 67\%).

${ }^{1} \mathrm{H}$ NMR $\left(600 \mathrm{MHz}, \mathrm{CDCl}_{3}\right) \delta 9.99(\mathrm{~s}, 1 \mathrm{H}), 7.86(\mathrm{~d}, J=8.0 \mathrm{~Hz}$, $2 \mathrm{H}), 7.64(\mathrm{~d}, J=8.1 \mathrm{~Hz}, 2 \mathrm{H}), 7.45(\mathrm{~d}, J=7.8 \mathrm{~Hz}, 2 \mathrm{H}), 7.27-7.19$ $(\mathrm{m}, 3 \mathrm{H}), 7.10(\mathrm{~d}, J=16.2 \mathrm{~Hz}, 1 \mathrm{H}), 2.38(\mathrm{~s}, 3 \mathrm{H}) .{ }^{13} \mathrm{C}$ NMR $(151$ $\left.\mathrm{MHz}, \mathrm{CDCl}_{3}\right) \delta 191.79,143.83,138.77,135.31,133.93,132.33$, $130.40,129.71,126.99,126.92,126.47,21.49$.

Synthetic Procedure for 5-(benzo[d]oxazol-2yl)thiophene-2-carbaldehyde (9):27 To a 1-dram (4 mL) vial equipped with a magnetic stir bar was added the benzo[ $d]$ oxazole $(0.1 \mathrm{mmol}, 1$ equiv $)$, thiophene-2carbaldehyde ( $0.2 \mathrm{mmol}, 2$ equiv), silver acetate (AgOAc) $(0.2$ mmol, 2 equiv), and $( \pm)$-2a $(0.05 \mathrm{mmol}, 5 \mathrm{~mol} \%)$. To this mixture was added a 1:1 DMSO $(1 \mathrm{~mL}, 0.1 \mathrm{M})$. The vial was capped and placed on a preheated hotplate at $110{ }^{\circ} \mathrm{C}$ and stirred at $500 \mathrm{rpm}$ for $12 \mathrm{~h}$. The reaction was removed from the stir plate and allowed to cool. The contents of the vial were transferred to a separation vial with subsequent washing of $\mathrm{H}_{2} \mathrm{O}$ and EtOAc. Additional $\mathrm{H}_{2} \mathrm{O}(50 \mathrm{~mL})$ was added to the separation vial, and the desired material was extraction with EtOAc $(3 \times 50 \mathrm{~mL})$ and dried with $\mathrm{Na}_{2} \mathrm{SO}_{4}$. After the solvent was removed in vacuo, the crude residue was purified by $\mathrm{SiO}_{2}$ gel column chromatography (5\% EtOAc/hexanes). Purification afforded 9 as a yellow solid (14 mg, 61\%).

${ }^{1} \mathrm{H}$ NMR (600 MHz, $\left.\mathrm{CDCl}_{3}\right) \delta 10.00(\mathrm{~d}, J=2.1 \mathrm{~Hz}, 1 \mathrm{H}), 7.97$ (dd, $J=3.9,2.1 \mathrm{~Hz}, 1 \mathrm{H}), 7.82(\mathrm{dd}, J=4.0,2.1 \mathrm{~Hz}, 1 \mathrm{H}), 7.79$ (dt, $J$ $=8.5,1.7 \mathrm{~Hz}, 1 \mathrm{H}), 7.63-7.57(\mathrm{~m}, 1 \mathrm{H}), 7.40(\mathrm{pt}, J=7.4,1.7 \mathrm{~Hz}$, $2 \mathrm{H}) .{ }^{13} \mathrm{C}$ NMR $\left(151 \mathrm{MHz}, \mathrm{CDCl}_{3}\right) \delta 183.00,157.81,150.82$, $146.39,141.97,137.78,136.25,130.04,126.37,125.41$, $120.61,110.93$

\section{ASSOCIATED CONTENT}

\section{AUTHOR INFORMATION}

\section{Corresponding Author}

*Email: Keary@Scripps.edu

\section{Present Addresses}

†If an author's address is different than the one given in the affiliation line, this information may be included here.

\section{Author Contributions}

The manuscript was written through contributions of all authors. / All authors have given approval to the final version of the manuscript. / \$These authors contributed equally. (match statement to author names with a symbol)

Notes

The authors declare no competing financial interest.

Supporting Information

Experiment details, spectra data, copies of NMR spectra, X-ray crystallographic data, and computational details. These materials are available free of charge via the Internet at http://pubs.acs.org.

\section{ACKNOWLEDGMENT}

This work was financially supported by the National Institutes of Health (5R35GM125052). We further acknowledge the National Science Foundation for a Graduate Research Fellowship (NSF/DGE-1842471, A.M.R.) and Hearst Foundations for supporting a high school internship (M.J.D.). We thank Dr. Jason S. Chen and staff at the Scripps Research Automated Synthesis Facility for assistance with analytical work as well as the Baran group for use of their HRMS. Furthermore, we thank Lea Dettling (Freie Universität Berlin) for scientific discussions and Lucas J. Oxtoby and Tanner C. Jankins for helpful suggestions in the preparation of this manuscript.

\section{ABBREVIATIONS}

NHC, $N$-Heterocyclic Carbene; CAAC, Cyclic (Alkyl)- and (Aryl)(Amino)Carbenes; $a \mathrm{NHC}$, abnormal $\mathrm{N}$-Heterocyclic Carbene; NXHC, $N, X$-Heterocyclic Carbene $(\mathrm{X}=0, \mathrm{P}, \mathrm{S}$, etc.); Pd(TFA), Palladium(II) Trifluoroacetate; 1,2-DCE, 1,2-Dichloroethane; HRMS, High-Resolution Mass Spectrometry; TFA, Trifluoroacetate; AgOTf, Silver(I) Trifluoromethansulfonate; AgOAc, Silver(I) Acetate.

\section{REFERENCES}

(1) For selected early reports, see: (a) Arduengo, A. J., III; Harlow, R. L.; Kline, M. A Stable Crystalline Carbene. J. Am. Chem. Soc. 1991, 113, 361-363. (b) Scholl, M.; Ding, S.; Lee, C. W.; Grubbs, R. H. Synthesis and Activity of a New Generation of Ruthenium-Based Olefin Metathesis Catalysts Coordinated with 1,3-Dimesityl-4,5-dihydroimidazol-2-ylidene Ligands. Org. Lett. 1999, 1, 953-956. (c) Hahn, F. E.; Wittenbecher, L.; Boese, R.; Bläser, $\quad$ D. $\quad N, N^{\prime}$-Bis $(2,2-$ dimethylpropyl)benzimidazolin-2-ylidene: A Stable Nucleophilic Carbene Derived from Benzimidazole. Chem. Eur. J. 1999, 5, 1931-1935. For reviews, see: (d) $N$-Heterocyclic Carbenes in Transition Metal Catalysis, 1st ed.; Glorius, F.; Springer-Verlag Berlin Heidelberg, 2007. DOI: 10.1007/978-3540-36930-1 (e) Herrmann, W. A., N-Heterocyclic Carbenes: A New Concept in Organometallic Catalysis. Angew. Chem., Int. Ed. 2002, 41, 1290-1309. (f) Hahn, F. E., Heterocyclic Carbenes. Angew. Chem., Int. Ed. 2006, 45, 1348-1352. (g) Cazin, C. S. J., $N$-Heterocyclic Carbenes. Dalton Trans. 2013, 42, 7254-7254.

(2) For reviews, see: (a) Arduengo, A. J., III. Looking for Stable Carbenes: The Difficulty in Starting Anew. Acc. Chem. Res. 1999, 32, 913-921. (b) Nelson, D. J.; Nolan, S. P. Quantifying and Understanding the Electronic Properties of N-Heterocyclic Carbenes. Chem. Soc. Rev. 2013, 42, 6723-6753. (c) Fliedel, C.; Schnee, G.; Avilés, T.; Dagorne, S. Group 13 Metal (Al, Ga, In, Tl) 
Complexes Supported by Heteroatom-Bonded Carbene Ligands. Coord. Chem. Rev. 2014, 275, 63-86. (d) Peris, E., Smart N-Heterocyclic Carbene Ligands in Catalysis. Chem. Rev. 2018, 118, 9988-10031. (e) Nesterov, V.; Reiter, D.; Bag, P.; Frisch, P.; Holzner, R.; Porzelt, A.; Inoue, S. NHCs in Main Group Chemistry. Chem. Rev. 2018, 118, 9678-9842. (f) Vivancos, Á.; Segarra, C.; Albrecht, M., Mesoionic and Related Less Heteroatom-Stabilized N-Heterocyclic Carbene Complexes: Synthesis, Catalysis, and Other Applications. Chem. Rev. 2018, 118, 9493-9586. (g) Danopoulos, A. A.; Simler, T.; Braunstein, P. N-Heterocyclic Carbene Complexes of Copper, Nickel, and Cobalt. Chem. Rev. 2019, 119, 3730-3961. (h) Doddi, A.; Peters, M.; Tamm, M. N-Heterocyclic Carbene Adducts of Main Group Elements and Their Use as Ligands in Transition Metal Chemistry. Chem. Rev. 2019, 119, 6994-7112.(i) Zhao, Q.; Meng, G.; Nolan, S. P.; Szostak, M. N-Heterocyclic Carbene Complexes in C-H Activation Reactions. Chem. Rev. 2020,120, 1981-2048. (j) Liang, Q.; Song, D. Iron N-Heterocyclic Carbene Complexes in Homogeneous Catalysis. Chem. Soc. Rev. 2020, $49,1209-1232$

(3) (a) Soleilhavoup, M.; Bertrand, G. Cyclic (Alkyl)(Amino)Carbenes (CAACs): Stable Carbenes on the Rise. Acc. Chem. Res. 2015, 48, 256-266. (b) Roy, S.; Mondal, K. C.; Roesky, H. W. Cyclic Alkyl(amino) Carbene Stabilized Complexes with Low Coordinate Metals of Enduring Nature. Acc. Chem. Res. 2016, 49, 357-369. For reviews, see: (c) Melaimi, M.; Soleilhavoup, M.; Bertrand, G. Stable Cyclic Carbenes and Related Species beyond Diaminocarbenes. Angew. Chem., Int. Ed. 2010, 49, 8810-8849. (d) Melaimi, M.; Jazzar, R.; Soleilhavoup, M.; Bertrand, G. Cyclic (Alkyl)(amino)carbenes (CAACs): Recent Developments. Angew. Chem., Int. Ed. 2017, 56, 10046-10068. (e) Paul, U. S. D.; Radius, U. What Wanzlick Did Not Dare To Dream: Cyclic (Alkyl)(amino)carbenes (CAACs) as New Key Players in Transition-Metal Chemistry. Eur. J. Inorg. Chem. 2017, 2017, 3362-3375. (f) Kundu, S.; Sinhababu, S.; Chandrasekhar, V.; Roesky, H. W. Stable Cyclic (Alkyl)(amino) Carbene (cAAC) Radicals with Main Group Substituents. Chem. Sci. 2019, 10, 4727-4741. (g) Jazzar, R.; Soleilhavoup, M.; Bertrand, G. Cyclic (Alkyl)- and (Aryl)- (amino)carbene Coinage Metal Complexes and Their Applications. Chem. Rev. 2020, 120, 4141-4168.

(4) For review, see: Sau, S. C.; Hota, P. K.; Mandal, S. K.; Soleilhavoup, M.; Bertrand, G. Stable Abnormal N-Heterocyclic Carbenes and Their Applications. Chem. Soc. Rev. 2020, 49, 1233-1252.

(5) For review, see: Eicher, T.; Hauptmann, S.; Speicher, A. The Chemistry of Heterocycles: Structures, Reactions, Synthesis, and Applications, 3rd ed.; Wiley-VCH: Weinheim, Germany, 2013.

(6) For review, see: Chien, S. W.; Yen, S. K.; Hor, T. S. A. N,SHeterocyclic Carbene Complexes. Aust. J. Chem. 2010, 63, 727741.

(7) For review, see: Schuster, O.; Yang, L.; Raubenheimer, H. G.; Albrecht, M. Beyond Conventional $\mathrm{N}$-Heterocyclic Carbenes: Abnormal, Remote, and Other Classes of NHC Ligands with Reduced Heteroatom Stabilization. Chem. Rev. 2009, 109, 3445-3478.

(8) Franco, D.; Marchenko, A.; Koidan, G.; Hurieva, A. N.; Kostyuk, A.; Biffis, A. Palladium(II) Complexes with $\mathrm{N}$ Phosphanyl- $N$-heterocyclic Carbenes as Catalysts for Intermolecular Alkyne Hydroaminations. ACS Omega 2018, 3, 17888-17894.

(9) McGuinness, D. S.; Cavell, K. J. Donor-Functionalized Heterocyclic Carbene Complexes of Palladium(II): Efficient Catalysts for $\mathrm{C}-\mathrm{C}$ Coupling Reactions. Organometallics 2000, 19, 741-748.
(10) Yang, L.; Guo, Q.; Xiao, Y.; Mao, P. Development of Chelating $N$-Heterocyclic Carbene Metal Complexes. Chin. J. Org. Chem. 2015, 35, 1834-1847.

(11) (a) Wolf, J.; Labande, A.; Daran, J.-C.; Poli, R. Nickel(II), Palladium(II) and Rhodium(I) Complexes of New NHCThioether Ligands: Efficient Ketone Hydrosilylation Catalysis by a Cationic Rh Complex. Eur. J. Inorg. Chem. 2007, 2007, 5069-5079. (b) Fliedel, C.; Schnee, G.; Braunstein, P. Versatile Coordination Modes of Novel Hemilabile $S$-NHC ligands. Dalton Trans. 2009, 2474-2476. (c) Yuan, D.; Huynh, H. V. Syntheses and Characterizations of Thiolato-Functionalized NHeterocyclic Carbene Pd(II) Complexes with Normal and Mesoionic Binding Modes. Dalton Trans. 2011, 40, 1169811703. (d) Yuan, D.; Huynh, H. V. Sulfur-Functionalized $N$ Heterocyclic Carbene Complexes of $\mathrm{Pd}(\mathrm{II})$ : Syntheses, Structures and Catalytic Activities. Molecules 2012, 17, 24912517. (e) Canovese, L.; Visentin, F.; Levi, C.; Santo, C.; Bertolasi, V. Synthesis of Novel Palladium Allyl Complexes Bearing Heteroditopic NHC-S Ligands. Kinetic Study on the Carbene Exchange between Bis-Carbene Palladium Allyl Complexes. J. Organomet. Chem. 2013, 732, 27-39. (f) Liu, Y.; Kean, Z. S.; d'Aquino, A. I.; Manraj, Y. D.; Mendez-Arroyo, J.; Mirkin, C. A. Palladium(II) Weak-Link Approach Complexes Bearing Hemilabile N-Heterocyclic Carbene-Thioether Ligands. Inorg. Chem. 2017, 56, 5902-5910. For a review, see: (g) Bierenstiel, M.; Cross, E. D. Sulfur-Functionalized $N$-Heterocyclic Carbenes and Their Transition Metal Complexes. Coord. Chem. Rev. 2011, 255, 574-590.

(12) (a) Huynh, H. V.; Yeo, C. H.; Chew, Y. X. Syntheses, Structures, and Catalytic Activities of Hemilabile ThioetherFunctionalized NHC Complexes. Organometallics 2010, 29, 1479-1486. (b) Huynh, H. V.; Chew, Y. X. Synthesis, Structural Characterization and Catalytic Activity of a Palladium(II) Complex Bearing a New Ditopic Thiophene- $N$-Heterocyclic Carbene Ligand. Inorg. Chim. Acta 2010, 363, 1979-1983. (c) Fliedel, C.; Braunstein, P. Thioether-Functionalized NHeterocyclic Carbenes: Mono- and Bis- $\left(S, C_{\mathrm{NHC}}\right)$ Palladium Complexes, Catalytic C-C Coupling, and Characterization of a Unique $\mathrm{Ag}_{4} \mathrm{I}_{4}\left(S, C_{\mathrm{NHC}}\right)_{2}$ Planar Cluster. Organometallics 2010, 29, 5614-5626. (d) Yuan, D.; Huynh, H. V. Dinuclear and Tetranuclear Palladium(II) Complexes of a ThiolatoFunctionalized, Benzannulated N-Heterocyclic Carbene Ligand and Their Activities toward Suzuki-Miyaura Coupling. Organometallics 2010, 29, 6020-6027. For a Ni-catalyzed Sukuki-Miyaura reaction, see: (e) Bernhammer, J. C.; Huynh, H. V. Nickel(II) Benzimidazolin-2-ylidene Complexes with Thioether-Functionalized Side Chains as Catalysts for SuzukiMiyaura Cross-Coupling. Organometallics 2014, 33, 58455851.

(13) Huynh, H. V.; Yuan, D.; Han, Y. Syntheses and Catalytic Activities of Pseudo-Pincer and CSC Pincer-Type Pd(II) Complexes Derived from Benzannulated N-Heterocyclic Carbenes. Dalton Trans. 2009, 7262-7268.

(14) Roseblade, S. J.; Ros, A.; Monge, D.; Alcarazo, M.; Álvarez, E.; Lassaletta, J. M.; Fernández, R. Imidazo[1,5-a]pyridin-3ylidene/Thioether Mixed C/S Ligands and Complexes Thereof. Organometallics 2007, 26, 2570-2578.

(15) (a) Yuan, D.; Tang, H.; Xiao, L.; Huynh, H. V. CSC-Pincer versus Pseudo-Pincer Complexes of Palladium(II): A Comparative Study on Complexation and Catalytic Activities of NHC Complexes. Dalton Trans. 2011, 40, 8788-8795. (b) Bernhammer, J. C.; Huynh, H. V. Benzimidazolin-2-ylidene Complexes of Palladium(II) Featuring a Thioether Moiety: Synthesis, Characterization, Molecular Dynamics, and Catalytic Activities. Organometallics 2014, 33, 1266-1275. 
(16) Bhaskar, R.; Sharma, A. K.; Singh, A. K. Palladium(II) Complexes of N-Heterocyclic Carbene Amidates Derived from Chalcogenated Acetamide-Functionalized $1 \mathrm{H}$ Benzimidazolium Salts: Recyclable Catalyst for Regioselective Arylation of Imidazoles under Aerobic Conditions. Organometallics 2018, 37, 2669-2681.

(17) Dubey, P.; Gupta, S.; Singh, A. K. Trinuclear Complexes of Palladium(II) with Chalcogenated $\mathrm{N}$-Heterocyclic Carbenes: Catalysis of Selective Nitrile-Primary Amide Interconversion and Sonogashira Coupling. Dalton Trans. 2017, 46, 1306513076.

(18) (a) Huynh, H. V.; Yeo, C. H.; Tan, G. K. Hemilabile Behavior of a Thioether-Functionalized N-Heterocyclic Carbene Ligand. Chem. Commun. 2006, 3833-3835. (b) Braunstein, P.; Naud, F. Hemilability of Hybrid Ligands and the Coordination Chemistry of Oxazoline-Based Systems. Angew. Chem., Int. Ed. 2001, 40, 680-699. For review, see: Pearson, R. G. Hard and Soft Acids and Bases-The Evolution of a Chemical Concept. Coord. Chem. Rev. 1990, 100, 403-425.

(19) Romine, A. M.; Yang, K. S.; Karunananda, M. K.; Chen, J. S.; Engle, K. M. Synthetic and Mechanistic Studies of a Versatile Heteroaryl Thioether Directing Group for Pd(II) Catalysis. ACS Catal. 2019, 9, 7626-7640.

(20) The relative stereochemistry of the major and minor diastereomers could be assigned by NOESY analysis of the bulk mixture. From this experiment we confirmed that it was indeed the major diastereomer and not the minor that was identified by single-crystal X-ray analysis.

(21) Yushina, I.; Tarasova, N.; Kim, D.; Sharutin, V.; Bartashevich, E. Noncovalent Bonds, Spectral and Thermal Properties of Substituted Thiazolo[2,3-b][1,3]thiazinium Triiodides. Crystals 2019, 9, 506.

(22) Cabeza, J. A.; del Río, I.; Sánchez-Vega, M. G.; Suárez, M. Methyl Levamisolium Triflate as a Precursor to a Chiral Bifunctional N-Heterocyclic Carbene-Thiolate Ligand: Palladium(II) Complexes. Organometallics 2006, 25, 18311834.

(23) (a) Pendleton, I. M.; Pérez-Temprano, M. H.; Sanford, M. S.; Zimmerman, P. M. Experimental and Computational Assessment of Reactivity and Mechanism in $\mathrm{C}\left(\mathrm{sp}^{3}\right)-\mathrm{N}$ BondForming Reductive Elimination from Palladium(IV). J. Am. Chem. Soc. 2016, 138, 6049-6060. (b) Park, H.; Verma, P.; Hong, K.; Yu, J.-Q. Controlling Pd(IV) Reductive Elimination Pathways Enables Pd(II)-Catalysed Enantioselective C(sp $\left.{ }^{3}\right)-\mathrm{H}$ Fluorination. Nat. Chem. 2018, 10, 755-762.

(24) Galliford, C. V.; Voronin, K.; Hesk, D.; Koharski, D.; McNamara, P. Rapid Synthesis of a ${ }^{13} \mathrm{C}_{6}$-Benzothiazolium Salt from ${ }^{13} \mathrm{C}_{6}$-Aniline. J. Labelled Comp. Radiopharm. 2011, 54, 229-232.

(25) Ackermann, L.; Potukuchi, H. K.; Althammer, A.; Born, R.; Mayer, P. Tetra-ortho-Substituted Biaryls through PalladiumCatalyzed Suzuki-Miyaura Couplings with a Diaminochlorophosphine Ligand. Org. Lett. 2010, 12, $1004-$ 1007.

(26) Xu, H.-J.; Zhao, Y.-Q.; Zhou, X.-F. Palladium-Catalyzed Heck Reaction of Aryl Chlorides under Mild Conditions Promoted by Organic Ionic Bases. J. Org. Chem. 2011, 76, 80368041.

(27) Xi, P.; Yang, F.; Qin, S.; Zhao, D.; Lan, J.; Gao, G.; Hu, C.; You, J. Palladium(II)-Catalyzed Oxidative $\mathrm{C}-\mathrm{H} / \mathrm{C}-\mathrm{H}$ Cross-Coupling of Heteroarenes. J. Am. Chem. Soc. 2010, 132, 1822-1824.

(28) CCDC 1905653 (6c'), 1905643 (6d), 1905647 (6e), 1905650 (6g), 1905652 (6j'), 1905649 (6u), 1905646 (6x), 1905644 (9), 1905651 (17), 1905645 (20), 1905648 (22), 1905654 (Pd-1), and 1905655 (Pd-2) contain the supplementary crystallographic data for this paper. These data can be obtained free of charge from The Cambridge Crystallographic Data Centre via www.ccdc.cam.ac.uk/data_request/cif. 


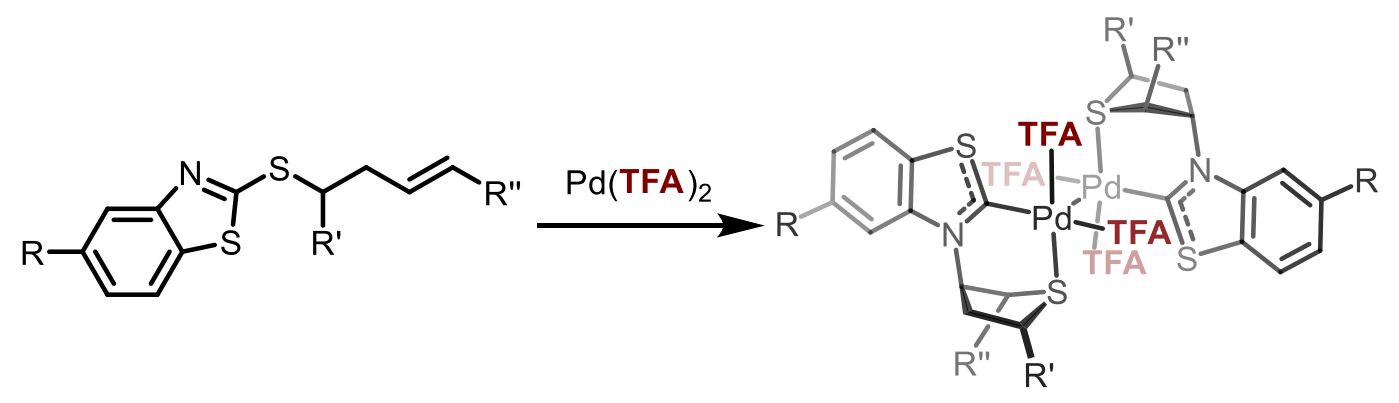

